\title{
CONSUMER ATTENTION ONLINE: HOW TO BE VISIBLE?
}

\section{Grigaliūnaitè V., Pilelienè L.}

The axiom "unseen - unsold" implies that marketing communication cannot be effective if it does not bypass the filter of attention, which is difficult in today's information clutter. As internet has emerged as powerful channel for marketing communication, the same axiom applies to the online marketing communication. In this research the analysis and synthesis of scientific literature as well as two eye tracking experiments are applied for the analysis of internet context-related elements influencing consumer visual attention and as a consequence having influence on consumer behavior. As a result, the guidelines for the selection of advertising message-related factors and advertisement's position in the internet news portals are provided. Moreover, recommendations for the attraction of consumer visual attention in the search engines are presented.

Keywords: visual attention; consumer behavior; online advertising; eye tracking JEL classification: M31, M37

\section{Introduction}

In information society, the Internet is a key instrument for creation, distribution, and manipulation of information. Accordingly, internet has emerged as a powerful channel for marketing communication leading to the concept of online advertising in becoming central to the entire discipline of marketing. As online advertising challenges the dominance of traditional advertising media (e.g., newspapers, television) (Belanche et al., 2017), a considerable literature has grown up around the theme of its effectiveness and debate continues about the best online advertising strategies. Estrada-Jiménez et al. (2017) considers online advertising as the pillar of the "free" content on the Web, stating that it has revolutionized the marketing business in recent years by creating a myriad of new opportunities for advertisers to reach potential customers. Moreover, according to Kireyev et al. (2016), firms increasingly rely on online media to acquire consumers. Therefore, to avoid the common mistakes the research is needed to determine and substantiate online advertising usage patterns.

To date, there are many studies that have investigated the influence of the context of internet on the online advertising effectiveness. However, such approaches have failed to address no context-dependent advertising message-related factors. By taking systems approach, the assumption could be made that all of the online advertising elements, that are message-related as well as context-related factors can have impact on online advertising effectiveness by influencing consumer response and behavior. While achieving to contribute to scientific discussion on advertising effectiveness, the research aims to provide a holistic approach to elements of online marketing communication that influence consumer behavior by analyzing context-related elements. The study integrates results from previous researches, which emphasize the differences of contextual impact on consumer reactions to message-related factors. Based on the theoretical analysis, two eye tracking experiments are presented in order to substantiate the influence of the context-related online marketing communication elements on consumer visual attention. 
Achieving to provide a substantial theoretical background for further studies on online marketing communication effectiveness, theoretical analysis and synthesis are provided. Comparative analysis of previous researches is performed to substantiate the different impacts of advertising contexts on the performance of message-related factors. Moreover, empirical neuromarketing research is provided to attain the objective of the article.

In order to reach the aim of the research, the article is organized as follows. First, we present the theoretical background and previous research on advertising structure, its elements and we analyze parts affecting the effectiveness. Based on the analysis and synthesis of scientific literature, online marketing communication elements lacking theoretical substantiation regarding their effectiveness are revealed. Subsequently, we present research methodology and results. Finally, conclusions are provided.

\section{Theoretical Substantiation}

The evolution of electronic media and the increasing role of online advertising within marketing strategies have created space for both researchers and practitioners to explore new areas (Jankowski et al., 2016). According to Estrada-Jiménez et al. (2017), the advent of the Internet and the Web has created a myriad of new opportunities for advertisers to target billions of people almost effortlessly.

Communication effectiveness depends on the goals of the campaign and the specific advertisement (Belanche et al., 2017). According to McGuire (1976) the consumer information-processing starts with exposure, which causes attention and perception. Only then it will come to comprehension, leading to purchase. Therefore, in a framework of any communicational goal, it can be stated that the effectiveness of advertising highly depends on the factors that attract consumers' attention, elicit advertising recall and recognition. According to Tackx et al. (2017), the traditional view to advertising goes as follows: a company takes an action (creates and releases advertising) that has an impact on the customer (changes the perception of needs and/or expectation), such that he or she takes a subsequent action (purchases an advertised object) that modifies the firm's position in the market. However, analyzing advertising interactivity, Jankowski et al. (2016) come to conclude that online advertising differs from traditional in its outcomes, e.g. the focus placed on maximizing user engagement in online advertising negatively affects the user experience because of advertising clutter and increasing intrusiveness. Therefore, the specific features and influences of this marketing tool demand further consideration (Belanche et al., 2017).

Many factors influencing attention to advertising and its effectiveness have been analyzed in scientific literature. The most basic categorization of those factors might be their division into external and internal. External factors are context-specific factors depending on advertising media, e.g. television, outdoor, etc. The other category, internal factors, is further classified into personal factors (laying a background for consumer segmentation) and advertising message-related factors (Walliser, 1997; Franch et al., 2013). Whereas external context-related factors are harder to control, the advertising message-related factors are the ones that marketers can gain advantages from. Therefore, advertising message-related factors are gaining their attention in scientific research (Pieters et al., 2002; Pieters and Wedel, 2004; Boerman et al., 2011).

Previous research on advertising effectiveness (see Pilelienè et al., 2015) enabled the determination of advertising message-related factors that must be considered to achieve and gain better effectiveness: 
- Different advertising layouts.

- Visual and textual elements.

- Advertising complexity level.

- Advertising source.

In a context of static advertising, all its components can be classified into visual and textual. Both groups mixed together compose advertising layout (see Figure 1). Moreover, the composition of the elements (i.e. visual and textual) in a layout determines the level of its complexity.

Previous research (see Grigaliūnaite et al., 2016) led to the conclusion that scientific research regarding the influence of message-related factors on the effectiveness of advertising is scarce; the most discussed message-related factors were found to be the headline, dominating elements, and the number of elements. Therefore, the eye-tracking procedure was performed and compositions of message-related factors influencing the effectiveness of advertising were determined:

- Headline larger than the body text.

- A large number of elements with dominating textual elements.

- The emphasised brand.

As the combination of different visual and textual elements results in layout complexity, the research was provided to determine the differences in the impact of different levels of layout complexity on advertising effectiveness (see Pilelienè and Grigaliūnaitè, 2016). The research results determined guidelines for the strategic usage of advertising layout complexity: initial usage of the low complexity of advertising layout helps organizations in creating brand awareness and familiarity; after the brand gains its position in consumer memory, the higher level of advertising layout complexity has to be provided to create an emotional value. Moreover, the results of the research provided in a framework of fast-moving consumer good category (see Pilelienè and Grigaliūnaite, 2017) indicated that the brand should be presented in the top of the advertisement's layout.

Considering different message-related elements of advertising, the remaining important antecedent of its effectiveness is advertising source. According to Pi-Fang (2009), a properly selected advertising source positively affects consumer perception and confidence in a product, while an improper source can even cause negative effects. Despite the existence of many different kinds of advertising sources (mainly classified into spokes-persons and spokes-characters based on their nature), the most widely used sources are celebrities and non-celebrities - regular persons. Previous research on the effectiveness of advertising source (see Grigaliūnaitè and Pilelienè, 2015) enabled the determination of the following patterns: to enhance a level of consumers' purchase intentions a celebrity spokesperson has to be chosen; however, on purpose of improving brand awareness a non-celebrity spokesperson might cause a better result than some well-known person due to vampire effect. However, if the aim of the advertising campaign is attitude formation, then selecting a celebrity as an advertising spokesperson is recommended (Pilelienè and Grigaliūnaitè, 2017). Moreover, latter research revealed that visual attention to the brand presented in the static advertisements lowers according to letter " $Z$ " pattern and the most attention-grabbing brand position in the advertisement is the upper left corner. 


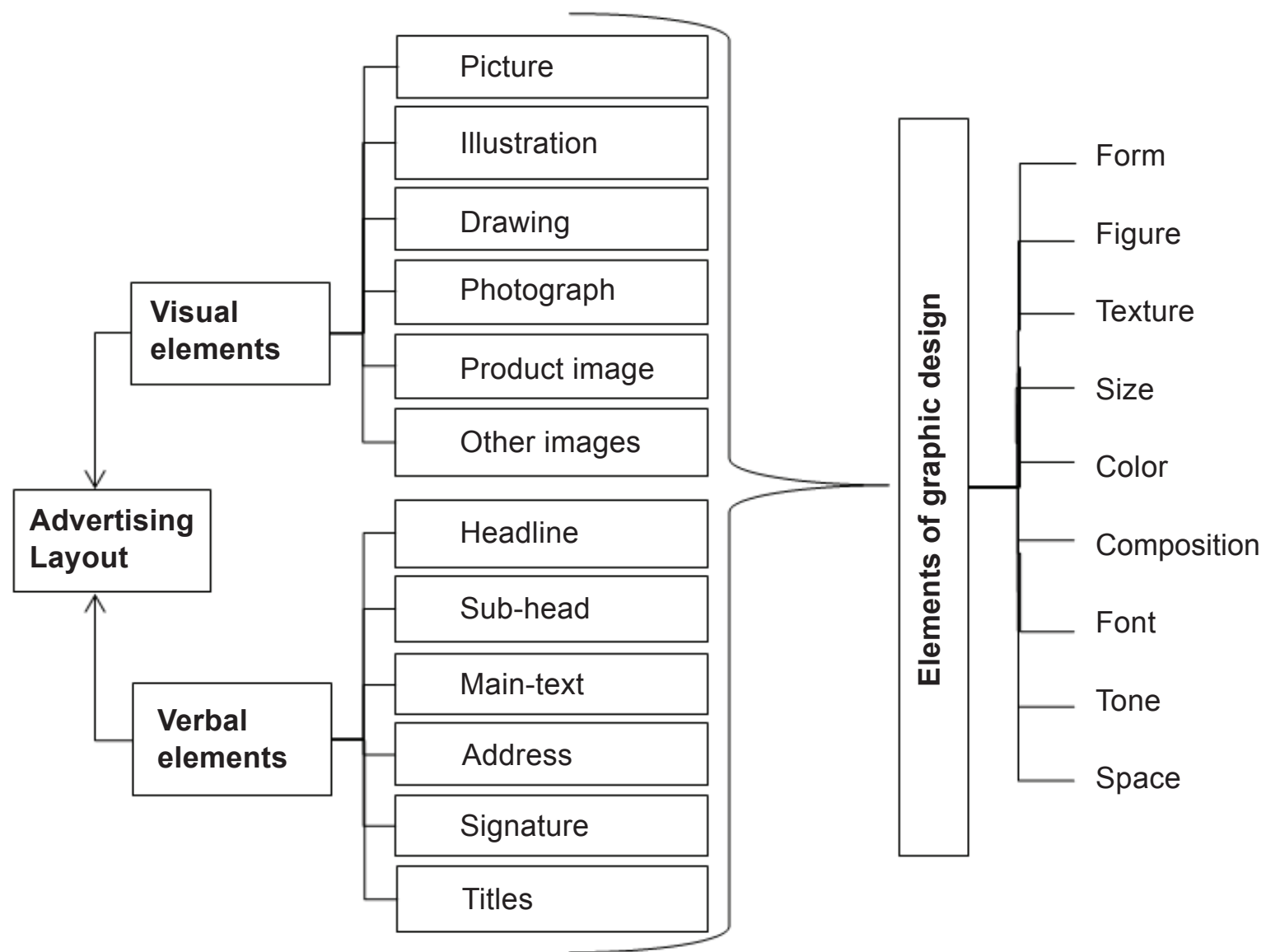

Source: self-elaboration based on Van Gisbergen et al. (2004), Hewett (2009), Kazlauskaite and Liakaitė (2009), Zubcevic and Luxton (2011).

Nevertheless, it can be argued that visual attention to the brand presented in the static advertisement differs due to the context of the advertisement. Hence, the influence of the context of internet on the visual attention to the advertisement itself, brand presented in it, and other relevant information, which is required but not sufficient condition for online marketing communication effectiveness, is further analyzed. More specifically, as the most attention-grabbing brand position in the advertisement is already determined, the question rises what is the most attention-grabbing advertisement's position in the context of internet. Moreover, as much of the information in the internet is gathered through search engines, the question rises what is the most attention-grabbing position in the search engine results pages. Hence, latter questions are of the interest for the further analysis.

\section{Methodology}

Based on the theoretical analysis and synthesis, if the aim of marketing communication is to form attitude or influence behavior, then recommended advertising message-related factors are: 
- Headline larger than the body text.

- A large number of elements with dominating textual elements.

- The emphasized brand.

- Higher level of advertising layout complexity.

- Celebrity spokesperson.

- Brand presented in the upper left corner.

Hence, considering the internet context and the two questions raised, the position of the advertisement with the recommended advertising message-related factors is the first unknown variable. The positions of the row in the search engine results pages is the second unknown variable. Both are analyzed in this research composed of two parts each part for each unknown variable.

The first part of the research is aimed to analyse the influence of the context of internet on the visual attention to the advertisement and brand. For the analysis of the influence of the context of internet on the visual attention to the advertisement, brand authors chose the pattern of the first page of the most-read internet news portal in the experiment holding country. The patterns of the internet news portals were chosen due to their popularity among consumers in most of the countries. Based on the recommended advertising message-related factors, the advertisement with the well-known celebrity spokesperson and the real brand (representing the category of fast-moving consumer goods) presented in the upper left corner of the advertisement was created and approved by experts of marketing and advertising.

The same advertisement was incorporated into the pattern of the news portal four times, each time into different position (see Figure 2):

- Upper position of the whole width of the news portal.

- $1 / 3$ width, right side, upper position of the news portal.

- $\quad 1 / 3$ width, right side, lower position of the news portal.

- $2 / 3$ width, left side of the news portal in the bottom.

All of the positions of the experiment advertisements are real most popular positions used in the internet news portals. Under the advertisement presented in the upper position of the whole news portal, a search box is presented. Above the advertisement presented in the bottom of the news portal and in the left side from the advertisements presented in the right side of the news portal the articles with the latest news are presented.

Based on such design, when all of the advertisements for the research are of the same layout, the influence of advertisements' layout on the results is eliminated.

All of the news portal patterns with the created advertisements each time in the different position were shown to the participants in a randomized order using Matlab R2012b software package on the computer screen (resolution: 1366x768); participants looked at the advertisements at their own pace and controlled the switch of advertisements by clicking the computer mouse. In between the news portal patterns with the created advertisements, the interstimulus (black screen) appeared for two seconds to eliminate the influence of the last seen pattern on the trajectory of gaze. Each portal pattern with the created advertisement was shown for the participants two times. Participants were told to read the pattern as they usually read (or not) the first page of the internet news portal. 
Figure 2 | The grid of the research (Br. meaning Brand)
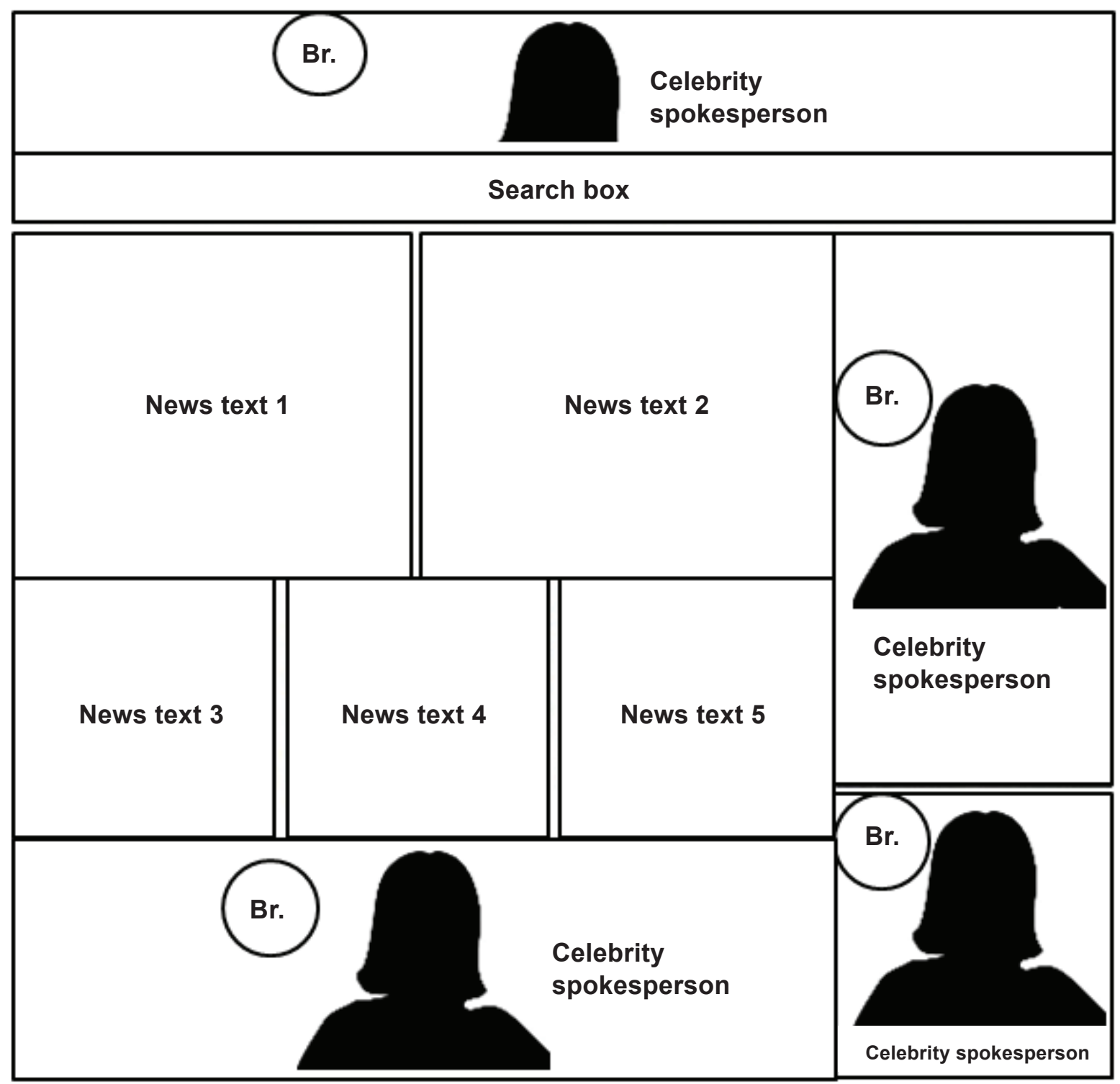

Source: author's elaboration

The experiment was conducted using Tobii Eye-Tracking Glasses - mobile videobased eye tracker recording monocular gaze data from the right eye at a sampling rate of $30 \mathrm{~Hz}$. This eye tracker has an accuracy of $0.5^{\circ}$. The system has a camera to record a scene video with a resolution of $640 \times 480$ pixels; maximum recording angles are $56^{\circ}$ of visual angle in horizontal and $40^{\circ}$ of visual angle in vertical direction.

Each of the participants put on the glasses and performed a standard nine point calibration. All of the participants were volunteers and were not paid for the participation in the eye-tracking experiment. Before the experiment, each of the participants was informed in detail about the experiment and signed the form of information and informed persons' consent. The experiment was held in Lithuania, Vytautas Magnus University, April, 2017.

10 participants' ( 6 females) data appropriate for the analysis were obtained. All of the participants were right-handed with normal or normal-to-corrected vision. All of the participants were at the age group of 18-29 years. 
For the analysis of eye-tracing results Tobii Studio v.3.2.3 software was applied. Advertisements and brands presented in the advertisements in different news portal positions: total fixation duration (average duration of all fixations within the specific element) and fixation count (average number of times the participants fixated on the specific element) were calculated. IBM SPSS Statistics v.20 and XLSTAT 2014 software packages were applied for the statistical analysis of the results obtained from the Tobii Studio v.3.2.3 software.

The second part of the research is aimed to analyse the influence of the position of the row in the search engine results pages on the visual attention and behavior (clicking the specific row). As the paid results' rows of search engine results page are only at the top / bottom of the left-hand column in the search engine results page and has a coloured advertisement's label next to it. It is usually less reliable than organic results (not paid), therefore, the object of this part of the research is organic results' rows (not paid) of search engine results page.

For the analysis of the influence of the position of the row in the search engine results pages on the visual attention and behavior, authors chose the pattern of the worldwide most popular search engine. Each of the participants were told that he or she would have to buy shoes online as he/she would really buy it and to put them into the cart. Then the same as in the first part of the research, Tobii Eye-Tracking Glasses were put on the participant and calibrated on the each of the participants for the most reliable results. After this, the participant was left alone in the room with the computer till he puts the shoes he chose into the cart.

All of the participants were volunteers and had not been paid for the participation in the eye-tracking experiment. The experiment was held in Lithuania, Vytautas Magnus University, May-June, 2017. Totally 10 participants ( 5 females) data appropriate for the analysis were obtained. All of the participants were right-handed with normal or normal-tocorrected vision. All of the participants were at the age group of 18-29 years from Europe, the reading pattern of the participants were from left to right and from top to bottom.

For the analysis of eye-tracing results Tobii Studio v.3.2.3 software was applied. Total fixation duration to the each of the organic results' rows of search engine results page till the click of the row from which the shoes were chosen to be bought was calculated. IBM SPSS Statistics v.20 software package was applied for the statistical analysis of the results obtained from the Tobii Studio v.3.2.3 software.

\section{Results}

First of all, the analysis of the first part of the research aimed to analyse the influence of the context of internet on the visual attention to the advertisement and brand is presented. The analysis of the research results revealed that the position of the advertisement that attracts the most visual attention regarding the internet news portal page is in the right side, $1 / 3$ width, upper position. The brand presented in the advertisement that is presented in latter position in the internet news portal page attracts the most visual attention as well (see Table 1). As it can be seen, the results of total fixation duration (mean viewing time) in seconds corresponds to the fixation count (times). Moreover, the percentage of brand viewing time from advertisement's viewing time in such case is substantial -93.7 percent. Hence, when brand is positioned in the left upper corner of the advertisement based on the recommendations for the message-related factors, and the position in the internet portal is chosen to be upper, $1 / 3$ width, right side, then advertisement not only attracts the most visual attention, but also does not detract attention from the core of the 
message - the brand. As it can be seen from the Table 1, the second position of the advertisement that attracts the most visual attention in the upper position of the whole width.

Table 1 | Average advertisement's (brand) viewing time in the internet news portal page

\begin{tabular}{|c|c|c|c|c|c|}
\hline Advertisement & $\begin{array}{c}\text { Total } \\
\text { fixation } \\
\text { duration } \\
\text { (s) }\end{array}$ & S.D. & $\begin{array}{c}\text { Fixation } \\
\text { Count } \\
\text { (times) }\end{array}$ & S.D. & $\begin{array}{l}\text { Percentage of } \\
\text { brand viewing } \\
\text { time from } \\
\text { advertise- } \\
\text { ment's viewing } \\
\text { time }\end{array}$ \\
\hline $\begin{array}{l}\text { Advertisement in the right side, } 1 / 3 \\
\text { width, upper position }\end{array}$ & 1.26 & 0.7 & 38.00 & 21.21 & \multirow{2}{*}{$93.7 \%$} \\
\hline $\begin{array}{l}\text { Brand in the advertisement in the } \\
\text { right side, } 1 / 3 \text { width, upper position }\end{array}$ & 1.18 & 0.82 & 35.50 & 24.75 & \\
\hline $\begin{array}{l}\text { Advertisement in the upper position } \\
\text { of the whole width }\end{array}$ & 1.20 & 0.57 & 36.50 & 17.68 & \multirow{2}{*}{$35 \%$} \\
\hline $\begin{array}{l}\text { Brand in the advertisement in the } \\
\text { upper position of the whole width }\end{array}$ & 0.42 & 0.36 & 13.00 & 11.31 & \\
\hline $\begin{array}{l}\text { Advertisement in the left side, } 2 / 3 \\
\text { width, in the bottom }\end{array}$ & 0.70 & 0.47 & 21.00 & 14.14 & \multirow{2}{*}{$7 \%$} \\
\hline $\begin{array}{l}\text { Brand in the advertisement in the } \\
\text { left side, } 2 / 3 \text { width, in the bottom }\end{array}$ & 0.05 & 0.07 & 1.50 & 2.12 & \\
\hline $\begin{array}{l}\text { Advertisement in the right side, } 1 / 3 \\
\text { width, lower position }\end{array}$ & 0.08 & 0.12 & 2.50 & 3.54 & \multirow{2}{*}{$62.5 \%$} \\
\hline $\begin{array}{l}\text { Brand in the advertisement in the } \\
\text { right side, } 1 / 3 \text { width, lower position }\end{array}$ & 0.05 & 0.07 & 1.50 & 2.12 & \\
\hline
\end{tabular}

Source: author's calculations

Nevertheless, in latter position brand viewing time is only 35 percent from the advertisement's viewing time. Despite this, latter position is the second regarding brand viewing time in the advertisement. In the third position is advertisement in the left side, $2 / 3$ width, in the bottom. In this position brand viewing time is only 7 percent from the advertisement's viewing time. Finally, the last position regarding advertisements viewing time is in the right side, $1 / 3$ width, lower position. In this position, brand viewing time is 62.5 percent from the advertisement's viewing time, but it corresponds to the brand viewing time in the advertisement that is positioned in the left side, $2 / 3$ width, in the bottom, just advertisement's in the right side, $1 / 3$ width, lower position viewing time is very low; hence, percentage of brand viewing time from advertisement's viewing time becomes high.

As the data of eye tracking experiment are non-normally distributed, the Friedman test is applied (four dependent samples) in order to evaluate whether there are significant differences in visual attention to the advertisements. As the test revealed, there are significant differences in visual attention to the advertisements. To examine where the differences actually occur, Wilcoxon Signed Ranks Test with the Bonferroni adjustment (significance level equals to 0.017) is applied as the Post-Hoc test (see Table 2). 
Table 2 | Wilcoxon Signed Ranks Test (for advertisements' viewing time)

\begin{tabular}{|l|c|c|c|c|c|c|}
\hline Statistics & $\begin{array}{c}\text { Upper } \\
\text { position - } \\
\text { Right upper } \\
\text { position }\end{array}$ & $\begin{array}{c}\text { Bottom } \\
\text { position - } \\
\text { Right upper } \\
\text { position }\end{array}$ & $\begin{array}{c}\text { Right lower } \\
\text { position - } \\
\text { Right upper } \\
\text { position }\end{array}$ & $\begin{array}{c}\text { Bottom } \\
\text { position } \\
\text { - Upper } \\
\text { position }\end{array}$ & $\begin{array}{c}\text { Right lower } \\
\text { position } \\
\text { - Upper } \\
\text { position }\end{array}$ & $\begin{array}{c}\text { Right lower } \\
\text { position } \\
\text { - Bottom } \\
\text { position }\end{array}$ \\
\hline $\mathbf{Z}$ & -1.309 & -2.879 & -2.879 & -1.309 & -2.879 & -2.879 \\
\hline p-value & 0.191 & 0.004 & 0.004 & 0.191 & 0.004 & 0.004 \\
\hline
\end{tabular}

Source: author's calculations

As indicated in Table 2, viewing time to the advertisement in the right side, 1/3 width, upper position is statistically significantly higher than to the advertisement in the left side, $2 / 3$ width, in the bottom or to the advertisement in the right side, $1 / 3$ width, lower position. Moreover, there is no statistically significant difference in viewing time to the advertisement in the right side, $1 / 3$ width, upper position and viewing time to the advertisement in the upper position of the whole width. Hence, the upper positions in the context of the internet attract most visual attention to the advertisements.

Due to the same conditions, the same procedure is applied for the analysis of differences in visual attention to the brand presented in the advertisements. As it can be seen, there is no statistically significant difference in viewing time to the brand presented in the advertisement in the right side, 1/3 width, upper position and viewing time to the brand presented in the advertisement in the upper position of the whole width. Moreover, there is absolutely no difference in in viewing time to the brand presented in the advertisement in the right side, $1 / 3$ width, lower position and viewing time to the brand presented in the advertisement in the left side, $2 / 3$ width, in the bottom. Nevertheless, viewing time to the brand presented in the advertisement in the right side, 1/3 width, upper position differs in a statistically significant from viewing time to the brand presented in the advertisement in the left side, $2 / 3$ width, in the bottom and from viewing time to the brand presented in the advertisement in the right side, 1/3 width, lower position. Furthermore, viewing time to the brand presented in the advertisement in the upper position of the whole width is statistically significantly higher than viewing time to the brand presented in the advertisement in the left side, $2 / 3$ width, in the bottom and viewing time to the brand presented in the advertisement in the right side, 1/3 width, lower position. Hence, the upper positions in the context of the internet attract most visual attention not only to the advertisements, but the brands presented in those advertisements as well. The position in the right side, 1/3 width, upper attracts most visual attention to the advertisement and the brand presented in that advertisement. If such positioning is not possible, then the second place that attracts most visual attention to the advertisement and the brand presented in that advertisement is in the upper position of the whole possible width. 
Table 3 | Wilcoxon Signed Ranks Test (for brands' viewing time)

\begin{tabular}{|l|c|c|c|c|c|c|}
\hline Statistics & $\begin{array}{c}\text { Upper } \\
\text { position - } \\
\text { Right upper } \\
\text { position }\end{array}$ & $\begin{array}{c}\text { Bottom } \\
\text { position - } \\
\text { Right upper } \\
\text { position }\end{array}$ & $\begin{array}{c}\text { Right lower } \\
\text { position - } \\
\text { Right upper } \\
\text { position }\end{array}$ & $\begin{array}{c}\text { Bottom } \\
\text { position } \\
\text { - Upper } \\
\text { position }\end{array}$ & $\begin{array}{c}\text { Right lower } \\
\text { position } \\
\text { - Upper } \\
\text { position }\end{array}$ & $\begin{array}{c}\text { Right lower } \\
\text { position } \\
\text { - Bottom } \\
\text { position }\end{array}$ \\
\hline $\mathbf{Z}$ & -1.309 & -2.879 & -2.879 & -2.879 & -2.879 & 0.000 \\
\hline p-value & 0.191 & 0.004 & 0.004 & 0.004 & 0.004 & 1.000 \\
\hline
\end{tabular}

Source: author's calculations

Figure 3 | The most attention-grabbing position of the advertisement in the context of the internet news portal page

The second best position for attracting visual attention

to the advertisement and brand presented in the advertisiment

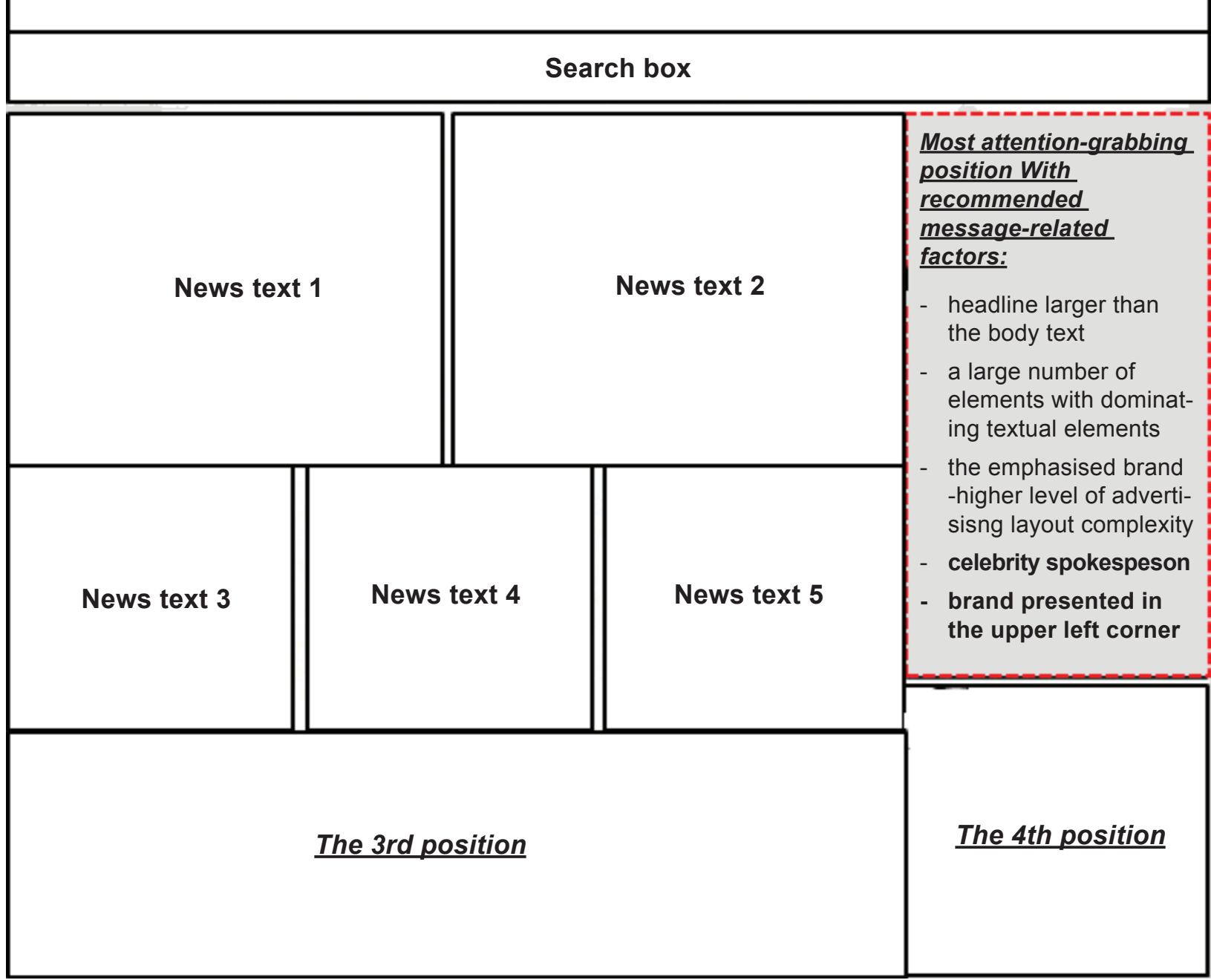

Source: author's elaboration

Based on the theoretical analysis in the research results, the model of online advertising elements that influence consumer behavior, revealing the most attention-grabbing 
position of the advertisement in the context of the internet news portal page and recommended message-related factors, is elaborated and presented in Figure 3 below. The two outlined (marked in bold) recommended message-related factors are the ones used in this research for the analysis of the influence of the context of internet on the visual attention to the advertisement and brand presented in the advertisement.

As it can be seen from the model, based on the research results, the most attention-grabbing position of the advertisement in the context of the internet news portal page is $1 / 3$ width, right side, upper position of the news portal. Based on the theoretical analysis, the advertisement in such position should contain: a headline larger than the body text, many elements with dominating textual elements, the emphasized brand, higher level of advertising layout complexity, celebrity spokesperson, and brand presented in the upper left corner of the advertisement. Based on the research results, the second best position of the advertisement in the context of the internet news portal page is the upper position of the whole width of the news portal. The third best position of the advertisement is $2 / 3$ width, left side of the news portal in the bottom. The last position of the advertisement, attracting least visual attention, is $1 / 3$ width, right side, lower position of the news portal. Despite this, not only position must be chosen, but at any position the advertisement should contain theoretically determined factors influencing consumer behavior in order to be effective.

Table 4 | Average viewing time to the organic results' rows of search engine results page

\begin{tabular}{|c|c|c|c|c|c|c|c|}
\hline \multirow{2}{*}{$\begin{array}{l}\text { Parti- } \\
\text { cipant }\end{array}$} & \multicolumn{5}{|c|}{ Total fixation duration (s) including zeros } & \multirow{2}{*}{ Keywords } & \multirow{2}{*}{ Click row } \\
\hline & 1st row & $\begin{array}{l}\text { 2nd } \\
\text { row }\end{array}$ & 3rd row & 4th row & 5 th row & & \\
\hline 1 & 0.00 & 1.20 & 0.26 & 3.70 & 1.63 & $\begin{array}{l}\text { "sneakers"; "buy"; } \\
\text { "online". }\end{array}$ & 4 \\
\hline 2 & 0.27 & 0.00 & 0.00 & 0.00 & 0.00 & Specific brand & 1 \\
\hline 3 & 1.63 & 0.32 & 0.33 & 0.03 & 0.00 & "shoes" & 1 \\
\hline 4 & 2.63 & 4.37 & 0.17 & 0.00 & 0.00 & "red"; "shoes". & 2 \\
\hline 5 & 2.56 & 2.26 & 0.00 & 0.00 & 0.00 & "shoes" & 2 \\
\hline 6 & 0.10 & 0.70 & 0.00 & 0.00 & 0.00 & "shoes" & 1 \\
\hline 7 & 0.13 & 0.00 & 0.00 & 0.00 & 0.00 & $\begin{array}{l}\text { Specific shoe shopping } \\
\text { centre }\end{array}$ & 1 \\
\hline 8 & 0.73 & 0.47 & 0.00 & 0.00 & 0.00 & "shoes"; “2017”. & 2 \\
\hline 9 & 0.00 & 0.00 & 0.53 & 0.00 & 0.00 & Shop of specific brand & 3 \\
\hline 10 & 0.33 & 0.03 & 0.12 & 0.00 & 0.00 & Specific brand & 1 \\
\hline $\begin{array}{l}\text { ave- } \\
\text { rage }\end{array}$ & 0.84 & 0.94 & 0.14 & 0.37 & 0.16 & $\begin{array}{l}\text { "Shoes" - } 5 \text { times; } \\
\text { Specific shop / brand / } \\
\text { type - } 5 \text { times; } \\
\text { Color / year - } 2 \text { times; } \\
\text { "Online" - } 1 \text { time; } \\
\text { "Buy" - time. }\end{array}$ & $\begin{array}{r}1^{\text {st }}-5 \text { times; } \\
2^{\text {nd }}-3 \text { times; } \\
3^{\text {rd }}-1 \text { time; } \\
4^{\text {th }}-1 \text { time; } \\
5^{\text {th }}-0 \text { times. }\end{array}$ \\
\hline
\end{tabular}

Source: author's calculations 
Furthermore, the analysis of the second part of the research aimed to analyse the influence of the position of the organic results' row in the search engine results pages on the visual attention and behavior (clicking the specific row) is provided. The analysis of the research results revealed that the positions of the organic results' rows in the search engine results pages that attracts the most consumer visual attention are the first one and the second one (see Table 4). As it can be seen, visual attention to the first row of the organic results in the search engine results pages is on average 0.84 seconds, and visual attention to the second row of the organic results in the search engine results pages is on average 0.94 seconds. Visual attention to the third row of the organic results in the search engine results pages is on average 0.14 seconds; to the fourth row -0.37 seconds, and finally to the fifth row -0.16 seconds. More of the rows were not analysed, because none of the participants have clicked on any further rows. Moreover, the first one and the second one row not only attracted the most visual attention, but got the most clicks and purchase intentions from the websites that were in these positions in the search engine results pages.

Figure 4 | The most attention-grabbing positions of the search engine results page (organic results)

Search engine

\section{Keywords}

1st row

$1 / 2$ of total clicks

2nd position for visual attention

Most

attentiongrabbing

2nd row

$1 / 3$ of total clicks

1st position for visual attention

positions

and most

clicks

$3 r d$ row

$1 / 3$ of total clicks

1 st position for visual attention

4th row

$1 / 10$ of total clicks

3rd position for visual attention

5th row

0 of total clicks

2nd position for visual attention 
The keywords that were the most used for the search in search engine contained the specific word of the name of product being searched and the specific shop / brand / type of product being searched that participants new and most likely are loyal for those brands / shops. Hence, this emphasizes the importance of the keyword selection for the internet pages on search engines.

Based on the research results, the most attention-grabbing positions of the search engine results page (organic results) are visualized in Figure 4 below. As it can be seen, the first row and the second row positions are the most attention-grabbing positions of the search engine results page regarding organic results. Moreover, the first row and the second row positions are the positions of the search engine results page regarding organic results that received the most clicks on them and enhance the possibility of consumer purchase intentions from the internet pages in latter positions of the search engine results page. The third row, the fourth row, and the fifth row positions of the search engine results page regarding organic results get significantly less consumer visual attention and significantly less clicks on latter rows. Thus, the possibility of consumer purchase intentions from the internet pages in latter positions of the search engine results page is much lower.

Consequently, it could be stated that the axiom "unseen - unsold" is relevant not only in the traditional marketing communication context, but in the internet context as well. In order to be seen in the search engine results page regarding organic results and in such a way enhance the possibility of consumer purchase intentions from the specific internet page, Search Engine Optimization should be applied.

\section{Conclusions}

Internet has emerged as a powerful channel for marketing communication leading to the concept of online advertising becoming central to the entire discipline of marketing. In a framework of any communicational goal, it can be stated that the effectiveness of advertising highly depends on factors that attract consumers' attention, elicit advertising recall and recognition. By taking systems approach, all of the online advertising elements, that are message-related as well as context-related factors can have impact on online advertising effectiveness by influencing consumers' attention, advertising recall and recognition, attitude, and finally behavior.

The analysis and synthesis of scientific literature leads to the conclusion that if the aim of marketing communication is to form attitude or influence behavior, then recommended advertising message-related factors are: headline larger than the body text, a large number of elements with dominating textual elements, the emphasized brand, higher level of advertising layout complexity, celebrity spokesperson, and brand presented in the upper left corner of the advertisement.

The analysis of research results allows substantiating the theoretical assumption that message-related and context-related factors can have impact on online marketing communication effectiveness. Research results lead to the conclusion that the most attention-grabbing position of the advertisement and the brand presented in the advertisement in the context of the internet news portal page is $1 / 3$ width, right side, upper position of the news portal. The second best position of the advertisement in the context of the internet news portal page is upper position of the whole width of the news portal. Nevertheless, 
advertisements in such positions should contain well managed message-related factors in order to improve the possibility to create effective advertising campaigns influencing consumer behavior. Moreover, advertisements in the news portal pages despite their position must be in the alliance with the news portal information.

The analysis of research results also allows making the conclusion that the first row and the second row positions are the most attention-grabbing positions of the search engine results page regarding organic results. Also, latter rows get the most clicks and enhances the possibility of consumer purchase intentions from the internet pages in latter positions of the search engine results page. Consequently, as "unseen is unsold", it is relevant to apply Search Engine Optimization.

The limitation of this research is the absence of the analysis of consumer visual attention regarding marketing communication in social networks. On the other hand, latter analysis becomes the guideline for future research.

\section{References}

Belanche, D., Flavián, C., \& Pérez-Rueda, A. (2017). Understanding interactive online advertising: Congruence and product involvement in highly and lowly arousing, skippable video ads. Journal of Interactive Marketing, 37, 75-88.

Boerman, S. C., Smit, E. G., \& van Meurs, L. (2011). Attention battle; the abilities of brand, visual, and text characteristics of the ad to draw attention versus the diverting power of the direct magazine context. In Advances in Advertising Research (Vol. 2) (pp. 295-310). Gabler.

Estrada-Jiménez, J., Parra-Arnau, J., Rodríguez-Hoyos, A., \& Forné, J. (2017). Online advertising: Analysis of privacy threats and protection approaches. Computer Communications, 100, 32-51.

Franch, E. B., \& Albiol, C. B. (2013). Messages with Impact: Creativity in Traditional Outdoor Advertising Platforms in Castellón (Spain) and Warrington (UK). Online Journal of Communication and Media Technologies, 3(2), 94.

Grigaliūnaitè, V., \& Pilelienè, L. (2015). Determination of the impact of spokesperson on advertising effectiveness. International Journal of Management, Accounting and Economics, 2(8), 810-822.

Grigaliūnaitè, V., Pilelienè, L., \& Bakanauskas, A. P. (2016). The analysis of the influence of internal factors on outdoor advertising effectiveness. In Research for rural development 2016: annual 22nd international scientific conference proceedings (pp. 166-173). Jelgava: Latvia University of Agriculture.

Hewett, G. (2009). Advertising \& Promotions. Pearson education.

Jankowski, J., Kazienko, P., Wątróbski, J., Lewandowska, A., Ziemba, P., \& Zioło, M. (2016). Fuzzy multi-objective modeling of effectiveness and user experience in online advertising. Expert Systems with Applications, 65, 315-331.

Kazlauskaitè, R., \& Liakaitè, R. (2009). Vaizdiniai reklamos elementai: pragmatinis tyrimas. Žmogus ir žodis, 1, 35-44.

Kireyev, P., Pauwels, K., \& Gupta, S. (2016). Do display ads influence search? Attribution and dynamics in online advertising. International Journal of Research in Marketing, 33(3), 475-490.

McGuire, W. J. (1976). Some Internal Psychological Factors Influencing Consumer Choice. Journal of Consumer Research, 2(4), 302-319. 
Pieters, R., Warlop, L., \& Wedel, M. (2002). Breaking through the clutter: Benefits of advertisement originality and familiarity for brand attention and memory. Management Science, 48(6), 765-781.

Pieters, R., \& Wedel, M. (2004). Attention capture and transfer in advertising: Brand, pictorial, and text-size effects. Journal of Marketing, 68(2), 36-50.

Pi-Fang, H. (2009). Evaluation of Advertising Spokespersons via the ANP-GRA Selection Model. Journal of Grey System, 21(1).

Pilelienė, L., Grigaliūnaitè, V., \& Bakanauskas, A. P (2015). Spausdintos reklamos efektyvumo vertinimo metodika. Kaunas: Vytauto Didžiojo universitetas.

Pilelienè, L., \& Grigaliūnaitè, V. (2016). Effect of visual advertising complexity on consumers' attention. International Journal of Management, Accounting and Economics, 3(8), 489-501.

Pilelienè, L., \& Grigaliūnaitè, V (2017). The effect of female celebrity spokesperson in FMCG advertising: neuromarketing approach. Journal of Consumer Marketing, 34(3), 202-213.

Tackx, K., Rothenberger, S., \& Verdin, P. (2017). Is advertising for losers? An empirical study from a value creation and value capturing perspective. European Management Journal, 35(3), 327-335.

Van Gisbergen, M. S., Ketelaar, P. E., \& Beentjes, J. W. J. (2004). Changes in advertising language? A content analysis of magazine advertisements in 1980 and 2000. In P. Neijens, C. Hess, B. van den Putte, E. Smit (Eds.), Content and Media Factors in Advertising (pp. 22-37). Amsterdam: Spinhuis Publishers.

Walliser, B. (1997). A Comparison of the Effectiveness of Perimeter and Outdoor Advertising: What Sponsorship can Learn from Outdoor Adevertising. Asia-Australia Marketing Journal, 5(1), 21-31.

Zubcevic, N., \& Luxton, S. (2011). A comparison of print advertisements from Australia and Croatia. Australasian Marketing Journal (AMJ), 19(2), 131-136.

\section{Authors}

\section{Viktorija Grigaliūnaitè}

Vytautas Magnus University

Faculty of Economics and Management, Marketing Department

S. Daukanto str. 28, Kaunas, LT-44299

Lithuania

viktorija.grigaliunaite@vdu.It

\section{Lina Pilelienè}

Vytautas Magnus University

Faculty of Economics and Management, Marketing Department

S. Daukanto str. 28

Kaunas, LT-44299, Lithuania

lina.pileliene@vdu.It 